\title{
Artificial intelligence and the endoscopist's skill and proficiency for polyp detection: no winner one without the other!
}

\author{
Franco Radaelli, Silvia Paggi \\ Division of Digestive Endoscopy and Gastroenterology, Valduce Hospital, Como, Italy \\ Correspondence to: Franco Radaelli, MD. Division of Digestive Endoscopy and Gastroenterology, Valduce Hospital, Via Dante 11, 22100, Como, Italy. \\ Email: francoradaelli01@gmail.com. \\ Comment on: Urban G, Tripathi P, Alkayali T, et al. Deep Learning Localizes and Identifies Polyps in Real Time With 96\% Accuracy in Screening \\ Colonoscopy. Gastroenterology 2018;155:1069-78.
}

Received: 18 December 2018; Accepted: 25 January 2019; Published: 05 January 2021.

doi: $10.21037 /$ tgh. 2019.01 .08

View this article at: http://dx.doi.org/10.21037/tgh.2019.01.08

Adenoma detection rate (ADR) represents the most widely accepted quality metric of colonoscopy and it has been validated as an independent predictor of the risk of interval colorectal cancer (CRC) after screening colonoscopy (1). Besides, it has also been demonstrated that increasing ADR translates into a reduced risk of interval CRC by individual endoscopist, with an approximately $6 \%$ relative reduction for each $1 \%$ increase in ADR (2). As ADR largely varies among different endoscopists $(1,3)$, reflecting differences in colonoscopy performance, many studies in the literature have evaluated new technologies to improve it, showing conflicting and sometimes disappointing results.

The study by Urban et al. (4), published on Gastroenterology, makes a further step in the future by evaluating the application of a deep learning model for computer-assisted image analysis [convolutional neural networks (CNNs)] to increase polyp detection, as a surrogate of ADR. In detail, the Authors developed and trained CNNs to detect polyps using a representative set of 8,641 polyp pictures from screening colonoscopies identified from more than 2,000 patients, achieving an accuracy of $96.4 \%$. The models were subsequently tested on 20 colonoscopy videos with an overall duration of five hours. Furthermore, highly-experienced endoscopists were asked to detect all polyps in 9 de-identified colonoscopy videos, selected from archived video studies, with or without benefit of the CNN overlay; their performances were compared with $\mathrm{CNN}$ ones using $\mathrm{CNN}$-assisted expert review as the reference. In the analysis of colonoscopy videos in which 28 polyps were removed, 4 expert reviewers identified
8 additional polyps without $\mathrm{CNN}$ assistance that had not been removed and identified during live examinations and 9 more polyps with $\mathrm{CNN}$ assistance. CNN identified all polyps detected by expert reviewers, with a false-positive rate of $7 \%$. The Authors concluded that $\mathrm{CNN}$ was able to identify polyps with a very high cross-validation accuracy in a set of colonoscopy pictures and also to real-time detect and localize polyps using an ordinary desktop equipment with a contemporary graphics processing unit. According to the Authors the use of artificial intelligence for polyp detection may represent a great promise in helping to close the gap between ADR and true adenoma prevalence, especially for colonoscopists with low baseline ADR.

So, if these results will be confirmed in real-time validation studies, will it be possible to disregard the human touch? Probably not, or at least not at all. Actually, the polyp and, even more, the adenoma detection during colonoscopy is a multistep process mainly depending on three main human contributors, which all concur to the quality of the examination.

First, the skill to bring the polyp into the field of view, which mainly depends on withdrawal technique, namely the ability of carefully inspecting the mucosa during the scope withdrawal by an adequate lumen distension, mucosal cleansing and mucosal exposure behind colonic folds. Technique, albeit difficult to be objectively assessed, is strictly endoscopist-related and represents a powerful indicator in differentiating high and low adenoma detectors, even more important than withdrawal time (5).

Second, the ability to focus attention on a lesion that is 
in the field of view. Studies evaluating the role of a second observer during colonoscopy in detecting adenomas suggest that even when the polyp is located within the field of view, the endoscopist may not perceive its presence $(6,7)$. This may be due to "inattentional blindness", when we fail to see something if our attention is focused somewhere else, or "change blindness", when changes are missed during eye movements or interruptions of visual scanning. Differences in visual tracking patterns between colonoscopists may also be a factor. At this purpose, studies evaluating the impact of endoscopists' visual gaze patterns on ADR by using the eye-tracking technology, an objective tool that detects differences in viewing patterns, defined distinct VGPs that are associated with expert behavior $(8,9)$.

Third, once that a lesion is put into the appropriate field of vision and correctly identified, the capacity to differentiate it from the normal surrounding mucosa or other subtle mucosal lesions with no clinical relevance. This mainly depends on the endoscopist experience and culture. The case of sessile serrated lesions, which have always existed but ever overlooked until recently, represents a relevant example of this situation.

How can the computer-assisted image analysis influence this multistep process? If it can be hypothesized that it can attenuate the endoscopists' deficiencies in attention or visual gaze patterns or fatigue, this new technology cannot compensate for poor colonoscopy technique. Indeed, the advantage of deep learning is just computational, as the machine can detect only what the colonoscope sees. Besides, the adoption of this new technology will not undo the role of the endoscopist in the correct interpretation of what the machine identifies, at least until future generations of deep learning polyp recognition software will substantially minimize the false-positive rate. As demonstrated in the present study, adding new training samples not only with more polyps, but also with random artifacts, such as water, air, bubbles, fecal matter and low quality blurred frames, could decrease the rate of false positive images.

In spite of that, the use of computer-aided detection systems for polyp detection during colonoscopy is extremely exciting and we are sure that in the near future these technologies will be part of modern endoscopy platforms.

However, at present some caution is needed as the study by Urban et al. still represents a feasibility study, and generalization to real-time use may be limited by several factors, for example the unknown effects of $\mathrm{CNN}$ on inspection behavior by the endoscopists (i.e., the availability of a highly-performing computerized support might reduce the operators' attention during colonoscope withdrawal and thus nullify the potential advantages of the new technology) or their acceptance of this auxiliary system, which still is suboptimal in other setting (i.e., radiology). Again, the issue of adjunctive costs for this technology is not negligible, either direct or indirect, due to an increase of procedure length and histology costs related to the problem of false positive results, which might even be more critical in case of poor bowel preparation. Future work must continue to develop methods that balance a high sensitivity with low latency and improved false positive rates, but at present the main efforts must still be paid for improving colonoscopy quality and endoscopists' training.

\section{Acknowledgements}

Funding: None.

\section{Footnote}

Provenance and Peer Review: This article was commissioned by the editorial office, Translational Gastroenterology and Hepatology. The article did not undergo external peer review.

Conflicts of Interest: Both authors have completed the ICMJE uniform disclosure form (available at http://dx.doi. org/10.21037/tgh.2019.01.08). The authors have no conflicts of interest to declare.

Ethical Statement: The authors are accountable for all aspects of the work in ensuring that questions related to the accuracy or integrity of any part of the work are appropriately investigated and resolved.

Open Access Statement: This is an Open Access article distributed in accordance with the Creative Commons Attribution-NonCommercial-NoDerivs 4.0 International License (CC BY-NC-ND 4.0), which permits the noncommercial replication and distribution of the article with the strict proviso that no changes or edits are made and the original work is properly cited (including links to both the formal publication through the relevant DOI and the license). See: https://creativecommons.org/licenses/by-nc-nd/4.0/.

\section{References}

1. Corley DA, Jensen CD, Marks AR, et al. Adenoma 
detection rate and risk of colorectal cancer and death. $\mathrm{N}$ Engl J Med 2014;370:1298-306.

2. Kaminski MF, Wieszczy P, Rupinski M, et al. increased rate of adenoma detection associates with reduced risk of colorectal cancer and death. Gastroenterology 2017;153:98-105.

3. Imperiale TF, Glowinski EA, Juliar BE, et al. Variation in polyp detection rates at screening colonoscopy. Gastrointest Endosc 2009;69:1288-95.

4. Urban G, Tripathi P, Alkayali T, et al. Deep Learning Localizes and Identifies Polyps in Real Time With 96\% Accuracy in Screening Colonoscopy. Gastroenterology 2018;155:1069-78.

5. Lee RH, Tang RS, Muthusamy VR, et al. Quality of colonoscopy withdrawal technique and variability in adenoma detection rates (with videos). Gastrointest Endosc 2011;74:128-34.

doi: $10.21037 / \operatorname{tgh} .2019 .01 .08$

Cite this article as: Radaelli F, Paggi S. Artificial intelligence and the endoscopist's skill and proficiency for polyp detection: no winner one without the other! Transl Gastroenterol Hepatol 2021;6:7.
6. Lee CK, Park DI, Lee SH, et al. Participation by experienced endoscopy nurses increases the detection rate of colon polyps during a screening colonoscopy: a multicenter, prospective, randomized study. Gastrointest Endosc 2011;74:1094-102.

7. Aslanian HR, Shieh FK, Chan FW, et al. Nurse observation during colonoscopy increases polyp detection: a randomized prospective study. Am J Gastroenterol 2013;108:166-72.

8. Almansa C, Shahid MW, Heckman MG, et al. Association between visual gaze patterns and adenoma detection rate during colonoscopy: a preliminary investigation. Am J Gastroenterol 2011;106:1070-4.

9. Lami M, Singh H, Dilley JH, et al. Gaze patterns hold key to unlocking successful search strategies and increasing polyp detection rate in colonoscopy. Endoscopy 2018;50:701-7. 